\section{ALFATHESIN Dose}

DEAR SIR,

Over a year ago I reported to you my experience with 677 cases of anaesthesia induced with alfathesin (Can. Anaes. Soc. J. 26: 516, 1979). Besides the known reactions to this drug, I encountered unusual side effects such as prolonged sleep, and rigidity with apnoea and cyanosis. As was mentioned, I was using the "minimal" dose recommended by the manufacturer, namely: $0.05 \mathrm{ml} / \mathrm{kg}$ body weight.

Following that report, I continued to use alfathesin for a total of 2,010 cases. Arterial blood gases, serum electrolytes (especially serum calcium and phosphorus) and liver enzymes were checked randomly in ten patients and were compared with the pre-operative values; but I did not find any significant change in these tests to explain the muscle rigidity, involuntary movements, or tachycardia.

Limiting the induction dose of alfathesin to $0.04 \mathrm{ml} / \mathrm{kg}$ body weight and avoiding the use of pancuronium for muscle relaxation in the last 1,200 cases, I did not encounter any of the reactions which were described in my previous letter, nor did I see any of the undesirable effects reported by the manufacturer.

I feel that the doses recommended for alfathesin by the manufacturer (between $0.05 \mathrm{ml} / \mathrm{kg}$ and $0.075 \mathrm{ml} / \mathrm{kg}$ ) are high if not unsafe. I also recommend that pancuronium be avoided when alfathesin is used for induction. All the patients induced with $0.04 \mathrm{ml} / \mathrm{kg}$ had a very smooth induction, and had no recollection of either the induction or the maintenance of anaesthesia.

Emil G. Bishay, M.D.,

Assistant Professor,

Anesthesiology,

University of California,

Los Angeles.

Cost of High and Low Flows of AnaesTHETIC AGENTS

DEAR SiR,

The letters in which Dr. Virtue compares the cost of anaesthesia with high and low flow systems (Canadian Anaesthetists' Society Journal 28: 182,1981$)$ conveys the impression that the so-called high flow systems are about 12 times more expensive.

Even as a strong advocate of a "high flow system", I have to concede that the circle absorber, used as a closed system, can provide for considerable economy when costly vapours such as enflurane are administered. However, for a fair comparison it must be pointed out that, while an average fresh gas flow of $51 / \mathrm{min}$ is by itself adequate for carbon dioxide removal, the low flow system with $500 \mathrm{ml} / \mathrm{min}$ must use sodalime for carbon dioxide elimination. Consequently the expense for sodalime is an essential factor in cost calculation of low flow anaesthesia.

In a recent letter to the Editor of Anesthesiology (Anesthesiology 54: 258, 1981) Dr. Edsall makes a calculation similar to that of Dr. Virtue and concludes that the cost of a nitrous oxide and halothane anaesthesia is about equal for the two systems if the expense of sodalime is included with the low flow system. Dr. Edsall calculated an hourly cost for sodalime of $\$ 0.88$ for a system with a flow of $500 \mathrm{ml} / \mathrm{min}$. For the 1000 -hour anaesthesia time used in Table II as a basis for cost calculation, $\$ 880$ would have to be added on the low flow side. It is obvious that this addition would change markedly the appearance of Dr. Virtue's balance sheet.

Even with the cost of sodalime added, the low flow system affords savings when expensive anaesthetic vapours are used. However, as Dr. Edsall pointed out, the popular technique employing nitrous oxide with narcotic supplementation and relaxants is actually less costly with a high flow system.

Dr. Virtue is a prominent member of a group of anaesthetists who champion low flow anaesthesia. Are the fortunes of the closed system so low that they have to be rescued by the overstatement of economic advantages through a rather biased account?

W.E. Spoerel, M.D., F.R.C.P.(C), Professor and Chairman, Department of Anaesthesia, The University of Western Ontario. 